\author{
Military Technical College \\ Cairo, Egypt
}

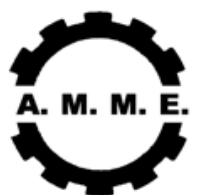

$12^{\text {th }}$ International Conference on Applied Mechanics and

Mechanical Engineering (AMME)

May 16-18, 2006

\title{
DESIGN OF AN EXPLOSIVELY FORMED PENETRATOR CAPABLE OF DEFEATING A SPECIFIC METALLIC TARGET
}

\author{
A. M. Riad*, M.M. Ismail* and E.A. Ibrahim**
}

\begin{abstract}
Design of a warhead that forms upon detonation an explosively formed penetrator (EFP) capable of penetrating a specific rolled homogeneous armor (RHA) is the main theme of this paper. Six different preliminary warhead models have been simulated using Autodyn-2D code. The main features of each EFP formed from each preliminary model are predicted. The obtained results serve in determining the design parameters of the required (refind) warhead model. In addition, the simulated EFP from the refined warhead model and its penetration into a specific RHA have been simulated.
\end{abstract}

Samples of the obtained predicted results by the code for EFPs formed from different preliminary and refined warhead models, respectively, are presented with relevant analysis and discussions. For the refined warhead model, the code predicts that the obtained EFP has a high velocity, high aspect ratio and is capable of penetrating the RHA to the specified thickness. Moreover, the influence of explosive type, its aspect ratio and liner material of the refined model on the formed EFP have been predicted.

\section{KEY WORDS}

Explosively formed penetrator, EFP formation process, penetration mechanics, and high-velocity impact phenomenon.

* Egyptian Armed Forces

** National Authority for Military Production, Factory No. 81. 


\section{INTRODUCTION}

Nowadays, future combat systems employing explosively formed penetrator (EFP) warheads, to defeat the most difficult targets at long standoff, are developed. These systems do not need to hit the target directly as shaped charge warheads. They also have higher secondary effects after target penetration than shaped charges. The main elements constituting EFP warhead are shown in Fig. 1 and the details of penetrator formation from its warhead have been reported in Ref. [1]. The formation process of EFP depends mainly on the explosive geometry and confinement, and the metallic liner geometry [2].

Several techniques for forming EFPs were presented in the open literature. Carleone [3] reported that various EFP shapes could be formed depending mainly on the explosive type, geometry and its confinement as well as the liner material and its geometry. He introduced the basic EFP shapes as shown in Fig.2. These shapes are named as: (i) long rods including forward and backward folded penetrators, cf. Figs. $2 a$ and $2 b$, and (ii) compact balls including point focus and W-fold, cf. Figs. $2 c$ and $2 d$.

The main methods used for designing and optimization of EFPs performance are classified into: (i) experimental methods and (ii) numerical methods. Numerous experiments with EFPs have been performed to study their formation processes as well as their terminal ballistic effects. The early stages of penetrator formation were monitored using flash X-ray units to determine its velocity and how it was formed. The EFPs could be captured in a soft-recovery system or fired against targets [4]. Due to a large number of parameters controlling the EFP formation, the experimental methods are very expensive. Numerical solution techniques are advanced to the point where calculations of EFP formation and penetration can be performed as a matter of routine on current wave propagation computer codes. Numerical results depend on the experience of the code users and their familiarities with the capabilities of the used code for simulations [5].

Recently, EFPs are designed using numerical modeling techniques in combination with results from experiments. These permit the designer to explore and narrow down the number of parameters prior to experiments, and provide insight into the mechanics governing the various stages of EFP formation and target penetration. Experimental results may be matched with the codes results, but these generally require specific adjustments to those problems.

Schweiger and Pohl [6] studied the effect of explosives materials on EFP formation. They simulated TNT, Comp B, Octol $75 \backslash 25$ and HMX explosives in their numerical investigation. They deduced that the kinetic energy and aspect ratio of the formed penetrator increased with the use of more energetic explosive. In addition, Weimann [2] proved experimentally that the charge length and its case thickness were the most important design parameters that could be available to the warhead designer for optimizing EFP performance. Their experimental results showed that the increase of 
the charge length and thickness of confinement case produced not only EFP with higher kinetic energy but also additional stretching of the formed EFP. Similar results are obtained by MacMahon et al [7] when they predicted that the increase in the charge length and thickness of confinement case led to a longer thinner EFP traveling with a high velocity.

Held [8] stated that the very wide apex angle cones began to approximate hemispherical liners of devices such as explosively formed penetrators. He deduced that the optimum formation of an EFP commenced only at an angle of $150^{\circ}$. In addition, Kishore et al. [9] investigated the role of the liner material and the methodology to evaluate the material in optimizing the performance of the formed EFP. They discussed the influence of mechanical and metallurgical parameters of the liner material on its velocity gradient absorption capability. They deduced that if the energy absorbed per unit volume (E/N) of the liner material is great, its capacity to absorb velocity gradient without failure was high indicating its high capacity to withstand explosive input energy. Thus, charges with high aspect ratio could be used for a particular design having liner materials with high (E/V) ratio. This liner material produced an integral penetrator with a high velocity. They also reported that the depth of the liner governed the original formed length of the penetrator; the velocity gradient between the pole and the rim of the formed penetrator was high when the depth of the liner was high.

Rondot [10] investigated experimentally and numerically the performance of EFP simulants against semi-infinite steel targets. Two sets of results showed that great efforts might be focused on forming the longest and unbroken penetrator to reach the highest performance. In addition, Weimann et al. [11] investigated experimentally and numerically the terminal ballistic effects of EFP on semi-infinite and spaced targets. For semi-infinite targets, their results showed that the increase in target strength from $700 \mathrm{MPa}$ to $1400 \mathrm{MPa}$ decreased the penetration performance of the EFPs with $30 \%$. For spaced targets, their results also showed the high influence of spacing between the plates on the penetration performance.

In the present work, the different EFPs formed from preliminary warhead models are simulated using Autodyn-2D code. The obtained predicted results of such models serve in setting the main design parameters of the refined warhead model. Both the formation of EFP from the refined warhead model and its penetration into RHA are simulated, respectively. Samples of the predicted results for the different EFPs simulated from preliminary and refined warhead models are presented, respectively. In addition, the influence of the main parameters of the refined warhead model on the formed EFP is predicted.

\section{DESCRIPTION AND SIMULATION OF PRELIMINARY MODELS}

In the following, six different preliminary warhead models have been designed. For each preliminary warhead model, the Autodyn-2D code is used to simulate its EFP formation process. The difference between warhead models is due to the change of 
liner dimensions and materials. The formation process results of EFPs serve in designing the refined warhead model. The code is also used to simulate the formation process of the refined EFP and its penetration into RHA, respectively.

All numerical techniques used in Autodyn-2D require the complex problem to be broken up into a finite number of smaller and simpler problems. This process is called discretization where all equations need to be discretized in time and space. To model the studied systems (EFP warheads), they should be drawn considering their datum point or zero origin. Each material or component is discretized into forming cells or meshes. Each mesh interacts with another one by defined strength model for each material that has an equation of state. The line of interaction between materials is defined; time step is determined in order to satisfy stability condition for the difference problem. Finally, a great matrix of unknowns is solved for non-linear system indicating each effect of stresses on the whole materials. The main representation procedures of the problem in the Autodyn-2D code are listed in Ref. [1].

\section{Description of Preliminary EFP Warhead Elements}

The Autodyn-2D code was provided with the data of the six preliminary warhead models. Each preliminary model was considered to consist of base, case, liner, and explosive charge. The main dimensions and material of each warhead element are listed in Ref. [1].

\section{Description of charge case}

The function of the warhead case is to provide confinement for explosive charge. The degree of

Confinement affects the EFP formation process and its velocity [2, 12]. For each preliminary warhead model, the selected material for filling the meshes of charge case grids was C45 steel. The equation of state for the case material was linear, whereas the used strength model was Von-Misses with no erosion model. The present form of this equation of state considering the initial elastic behavior expressed by an approximation to Hook's law is written as [13],

$$
\mathbf{P}=\mathbf{K} \mu
$$

Where $P$ is the pressure, $K$ is the bulk modulus of case material, $\mu$ is the material compressibility which is equal to $\left[\left(\rho / \rho_{0}\right)-1\right]$, where $\rho_{o}$ is the reference density of case material and $\rho$ is its current density. For Von-Mises strength model, the yield criterion is defined as [13]:

$$
1 / 2\left[\left(\sigma_{1}-\sigma_{2}\right)^{2}+\left(\sigma_{2}-\sigma_{3}\right)^{2}+\left(\sigma_{3}-\sigma_{1}\right)^{2}\right]=Y^{2},
$$

Where $\sigma_{1}, \sigma_{2}$ and $\sigma_{3}$ are the principal stresses, and $Y$ is the yield stress of the considered material. The input data to Autodyn-2D code for the case material are listed in Table 1. 


\section{Description of liner}

The liner is one of the most important EFP warhead elements. The factors associated with the metallic liner are material, geometry, and fabrication. The selected liner material for three preliminary models was C15 steel, whereas the liner material for the other preliminary models was OFHC cooper. The liner geometry includes its radius of curvature, diameter and thickness. For each preliminary warhead model, the main dimensions of the liner and its material are presented in Ref. [1]. The selected liner material was used for filling the meshes of liner elements in its simulated warhead. The equation of state for the liner materials was linear, whereas their strength model followed JohnsonCook equation. The erosion model when the formed EFPs started to penetrate RHA was selected to be incremental geometrical strain. The input data to Autodyn-2D code for the liner materials are listed in Table 1.

The Johnson-Cook model defines the stress $Y$ as [13]:

$$
Y=\left[A+B \epsilon_{p}{ }^{n}\right]\left[1+C \log \epsilon_{p}{ }^{*}\right]\left[1-T_{h}{ }^{n}\right],
$$

Where $A, B, C, n$, and $m$ are material constants, $\epsilon_{p}$ is the effective plastic strain, $\epsilon_{p}{ }^{*}$ is the normalized effective plastic strain rate, and $T_{h}$ is the homologous temperature which is expressed by:

$$
T_{h}=\left(T-T_{\text {room }}\right) /\left(T_{\text {melt }}-T_{\text {room }}\right),
$$

Where $T_{\text {room }}$ and $T_{\text {melt }}$ are room and melting temperatures of liner material, respectively. The expression in the first set of brackets of Eqn. (3) gives the stress as a function of strain when $\epsilon p^{*}=1.0 \mathrm{sec}^{-1}$ and $T_{h}=0$. The constant $A$ is the basic yield stress at low strains, whereas $B$ and $n$ represent the effect of strain hardening. The expressions in the second and third sets of brackets of the same equation represent the effects of strain rate and temperature, respectively.

\section{Description of explosive charge}

The explosive needed to fill each EFP warhead must have high velocity of detonation and high density to provide a high detonation pressure and results in fast EFP. The considered explosive material for filling the meshes of the explosive inside each EFP warhead was comp B. The equation of state for the considered explosive was "Jones-Wilkins-Lee" (JWL) equation, which gave the following energy equation [13]: 
Table 1. Input data to the code for the charge case and liner materials of preliminary warhead models, respectively.

\begin{tabular}{|c|c|c|c|}
\hline \multirow{2}{*}{ Parameter } & Charge case & \multicolumn{2}{|c|}{ Liner } \\
\cline { 3 - 4 } & C45 Steel & C15 Steel & OFHC Copper \\
\hline Reference density $\left(\mathrm{g} / \mathrm{cm}^{3}\right)$ & $7.8 \mathrm{E}+00$ & $7.8 \mathrm{E}+00$ & $8.96 \mathrm{E}+00$ \\
\hline Bulk modulus $(\mathrm{kPa})$ & $1.682 \mathrm{E}+08$ & $1.699 \mathrm{E}+08$ & $1.29 \mathrm{E}+08$ \\
\hline Specific heat $(\mathrm{c} . \mathrm{V}).\left(\mathrm{J} / \mathrm{kg}^{\circ} \mathrm{K}\right)$ & $0.0 \mathrm{E}+00$ & $4.5 \mathrm{E}+02$ & $3.83 \mathrm{E}+02$ \\
\hline Reference temperature $\left({ }^{\circ} \mathrm{K}\right)$ & $3.0 \mathrm{E}+00$ & $3.0 \mathrm{E}+02$ & $3.0 \mathrm{E} 2$ \\
\hline Shear modulus $(\mathrm{kPa})$ & $7.75 \mathrm{E}+07$ & $7.75 \mathrm{E}+07$ & $4.6 \mathrm{E}+07$ \\
\hline Yield stress $(\mathrm{kPa})$ & $3.13 \mathrm{E}+05$ & $2.45 \mathrm{E}+05$ & $9.0 \mathrm{E}+04$ \\
\hline Hardening exponent & 0.0 & $3.2 \mathrm{E}-01$ & $3.1 \mathrm{E}-01$ \\
\hline Hardening constant & 0.0 & $3.8 \mathrm{E}+05$ & $2.92 \mathrm{E}+05$ \\
\hline Strain rate constant & 0.0 & $6.0 \mathrm{E}-02$ & $2.5 \mathrm{E}-02$ \\
\hline Thermal softening exponent & 0.0 & $5.5 \mathrm{E}-01$ & $1.09 \mathrm{E}+00$ \\
\hline Erosion strain & 0.0 & $3.00 \mathrm{E}+00$ & $3.00 \mathrm{E}+00$ \\
\hline Melting Temperature, $\left[{ }^{\circ} \mathrm{k}\right]$ & $1.79 \mathrm{E}+03$ & $1.79 \mathrm{E}+03$ & $1.356 \mathrm{E}+03$ \\
\hline
\end{tabular}

$$
P=A \exp \left(r_{1} V\right)+B \exp \left(r_{2} V\right)+C V^{(1+w)}
$$

where $P$ is the pressure, $V$ is the relative volume, $A, B, C, r_{1}, r_{2}$, and $\omega$ are constants. For comp $B$, the values of the above mentioned constants are available in the material library of the used code. The parameter values of JWL equation fed into Autodyn-2D for comp B are listed in Table 2.

\section{Simulation of EFP Formation Process for the Preliminary Models}

Autodyn-2D code can represent the profile of EFP formation as function of time in addition to EFP pressure, velocity, stripping EFP and any type of contour levels. For simulating the EFP formation process of each model, the following procedures were followed: (i) select suitable subgrids for the configuration of warhead elements, (ii) for each element, zone the mesh in $(X, Y)$ and map it by $(I, J)$, (iii) fill the subgrids of warhead elements with their materials and set the initial conditions, and (iv) identify the initiation point and run the code.

EFP formation and its performance are strongly affected by the initial detonation wave front incident upon the warhead liner. The initiation method is an essential factor for the EFP performance since both the detonation wave shape and the associated pressure are strongly depended on the initiation method. The following procedures were followed to describe the point of initiation of the charge: (a) select the same subgrid of the simulated warhead model, (b) select a point on the axis of symmetry of the simulated model, (c) zone the mesh in $(X, Y)$, and (d) map it by $(I, J)$. Figure 3 represents the simulated warhead model (model 1) with the initiation point into Autodyn-2D code; target points are also plotted on the same figure. 
During the formation process, the liner is accelerated in axial and radial directions due to the detonation pressure. The detonation front has grazed the liner, and the expansion of the explosive products has started. When the formed liner attains its maximum momentum, the simulated explosive and charge case are removed. The removing process will be executed by deleting all Euler/Lagrange interactions, all polygons and all subgrids except the liner [13].

Table 2. Input data to the code for comp B.

\begin{tabular}{|c|c|}
\hline Parameter & Value \\
\hline Density $\left(\mathrm{g} / \mathrm{cm}^{3}\right)$ & 1.72 \\
\hline Parameter $\mathrm{A}(\mathrm{kPa})$ & $5.24 \mathrm{E} 8$ \\
\hline Parameter B $(\mathrm{kPa})$ & $7.68 \mathrm{E} 6$ \\
\hline Parameter $\mathrm{r}_{1}$ & 4.2 \\
\hline Parameter $\mathrm{r}_{2}$ & 1.1 \\
\hline $\mathrm{C}-\mathrm{J}$ detonation velocity $(\mathrm{m} / \mathrm{s})$ & $7.98 \mathrm{E} 3$ \\
\hline $\mathrm{C}-\mathrm{J}$ energy / unit volume $\left(\mathrm{kJ} / \mathrm{m}^{3}\right)$ & $8.5 \mathrm{E} 6$ \\
\hline C-J pressure $(\mathrm{kPa})$ & $2.95 \mathrm{E} 7$ \\
\hline Parameter $\omega$ & 0.34 \\
\hline
\end{tabular}

\section{DESCRIPTION AND SIMULATION OF THE REFINED WARHEAD MODEL}

\section{Description of the Refined Warhead Model}

Based on the formation process results for different preliminary EFPs, a refined warhead model has been designed. The charge case material of the refined warhead model was selected to be C37 steel, whereas the liner material was selected to be treated C10 steel. Comp B was selected to be the explosive material. Main dimensions of the refined warhead model were selected and its liner configuration had variable thickness.

\section{Simulation of EFP Formation Process for the Refined Model}

Similar procedures for simulating the formation process of each preliminary model were followed to simulate the same process for the refined model in Autodyn-2D code. The input data to the code for the charge case and liner materials used in the refined warhead model are listed in Table 3, respectively.

\section{Simulation of refined EFP interaction with a monolithic RHA}

Once the refined EFP was formed, a monolithic RHA with thickness of $150 \mathrm{~mm}$ was simulated. RHA was used for evaluating the performance of the refined EFP; this material had a Brinell hardness number ranged from 260-280 HB. The target material was entered into the code by a linear equation of state, an erosion model of incremental geometric strain, and a Johnson-Cook strength model. Input data of the target material to the code are also listed in Table 3 . The main procedures used to represent RHA into the code are listed in Ref. [1]. 
When the formed EFP was close to the target, the interaction mode in the code was activated. Figure 4 shows the formed EFP of the refined model in front of the monolithic RHA. The penetration of the formed EFP into the monolithic RHA was simulated to predict the following: (i) the penetration capability of such EFP into RHA, and (ii) the crater profile inside this armor. The EFP penetration process was terminated when the velocities of its nodes reached zeros. Moreover, pressure contours, eroded EFP nodes, stresses, and type of failure could be identified. Finally, both the crater depth and crater diameter were predicted.

\section{Erosion Algorithm}

Autodyn-2D includes an erosion algorithm that allows the automatically deletion of cells during calculation when their strain reaches the erosion strain value. This can be used with any of the available material models and allows the code to be used for very large deformation and deep penetration problems whilst retaining the speed and efficiency of the Lagrange processor. Eroded cells can be retained in the calculation as mass points and these continue to interact, by momentum transfer, with the automatically update the interact surfaces [13].

Table 3. Input data to the code for the charge case and liner materials of the refined warhead model as well as RHA material, respectively.

\begin{tabular}{|c|c|c|c|}
\hline Parameter & $\begin{array}{c}\text { Charge case } \\
\text { C37 Steel }\end{array}$ & $\begin{array}{c}\text { Liner } \\
\text { Treated C10 } \\
\text { Steel }\end{array}$ & $\begin{array}{c}\text { target } \\
\text { (RHA) }\end{array}$ \\
\hline Reference density $\left(\mathrm{g} / \mathrm{cm}^{3}\right)$ & $7.8 \mathrm{E}+00$ & $7.8 \mathrm{E}+00$ & $7.8 \mathrm{E}+00$ \\
\hline Bulk modulus $(\mathrm{kPa})$ & $1.68 \mathrm{E}+08$ & $1.699 \mathrm{E}+08$ & $1.64 \mathrm{E}+08$ \\
\hline Specific heat $(\mathrm{c} . \mathrm{v}).\left(\mathrm{J} / \mathrm{kg}^{\circ} \mathrm{K}\right)$ & $0.0 \mathrm{E}+00$ & $4.5 \mathrm{E}+02$ & $4.77 \mathrm{E}+02$ \\
\hline Reference temperature $\left({ }^{\circ} \mathrm{K}\right)$ & $3.0 \mathrm{E}+00$ & $3.0 \mathrm{E}+02$ & $3.0 \mathrm{E}+02$ \\
\hline Shear modulus $(\mathrm{kPa})$ & $7.75 \mathrm{E}+07$ & $7.75 \mathrm{E}+07$ & $8.18 \mathrm{E}+07$ \\
\hline Yield stress $(\mathrm{kPa})$ & $5.00 \mathrm{E}+05$ & $2.94 \mathrm{E}+05$ & $7.5 \mathrm{E}+05$ \\
\hline Hardening exponent & 0.0 & $3.2 \mathrm{E}-01$ & $2.6 \mathrm{E}-01$ \\
\hline Hardening constant & 0.0 & $3.8 \mathrm{E}+05$ & $5.1 \mathrm{E}+05$ \\
\hline Strain rate constant & 0.0 & $6.0 \mathrm{E}-02$ & $1.4 \mathrm{E}-02$ \\
\hline Thermal softening exponent & 0.0 & $5.5 \mathrm{E}-01$ & $1.03 \mathrm{E}+00$ \\
\hline Erosion strain & 0.0 & $3.00 \mathrm{E}+00$ & $1.00 \mathrm{E}+00$ \\
\hline Melting Temperature, $\left[^{\circ} \mathrm{k}\right]$ & $1.79 \mathrm{E}+03$ & $1.79 \mathrm{E}+03$ & $1.79 \mathrm{E}+03$ \\
\hline
\end{tabular}

\section{Time-step}

Since the numerical algorithm used in the code is an explicit scheme, there is optimum time step of integration, which must be determined to obtain a reasonable representation of solution. The local time step ensuring stability is calculated for each mesh point. The minimum value of all these local values multiplied by a safety factor (a default value of $2 / 3$ is built into the code) is chosen as the time step for the next 
update. In Lagrange mesh, the time step must satisfy the Courant condition [13]. This time step is represented by:

$$
\Delta \mathbf{t}<\mathbf{d} / \mathbf{c},
$$

where $\Delta t$ is the time step, $\mathrm{d}$ is the typical length of a zone (defined as the area of the zone divided by its longer diagonal), and $c$ is the local sound speed. This ensures that a disturbance does not propagate across a zone in a single time step. The minimum value of " $\Delta \mathrm{t}$ " must be found for all zones and this value will be used for all zones for the next time step of integration.

\section{Code Running}

Detonating the selected initiation point ran the code; the detonation of the explosive charge began. The detonation wave propagated in spherical shape with a detonation velocity higher than the sound velocity in the high explosive. The detonation parameters at each node in the explosive charge were calculated by the JWL equation with respect to the previous nodes at radial direction. The number of cycles at which both charge case and explosive removed was about 1000 . The total number of cycles was about 53000, whereas the expected time for the whole problem (including formation and penetration processes) was about $1000 \mu \mathrm{sec}$.

\section{RESULTS AND DISUCSSIONS}

In the following, the present results are: (i) formation process results of EFPs simulated from preliminary models, (ii) main features and formation process results of the refined EFP, (iii) parametric study using the refined EFP, and (iv) penetration results of EFPs formed from preliminary and refined warhead models, respectively.

\section{(i) Formation Process Results of EFPs Simulated from Preliminary}

\section{Models}

Autodyn-2D code has been used to understand the physical process associated with EFP formation. Moreover, the used code has the ability to investigate the influence of the different warhead elements on EFP performance quickly and efficiently. The effects of each warhead element on EFP shape, velocity, kinetic energy, formation time, final material condition and the propensity to remain as one coherent mass were predicted. The explosive charge, case and its base were removed for each simulated model when the liner attained its maximum momentum. Then, the code was continuously run until the time at which the penetrator was fully formed.

Autodyn-2D code has been run to simulate the EFP formation process for each preliminary model. Upon detonation, the detonation wave front reached the center of the liner. The pressure associated with the detonation wave deformed the liner and the detonation products distributed in different directions. Both the case and base materials were subjected to gross deformation because of their small thickness. The pressure acted on the deformed liner accelerated it in axial and radial directions. For 
model 1, the predicted time at which the deformed liner having its maximum momentum was $22.4 \mu \mathrm{s}$. The simulation process continued until all the portions of the deformed liner had the same momentum. At this moment, the transfer of the formed liner into EFP was completed and the EFP formation process was terminated. The produced EFP then flew towards the monolithic RHA.

Figure 5 shows the predicted time history of the complete formation process of the C15 steel liner of model 1 under the action of Comp B detonation. The predicted total time of formation process is $279 \mu \mathrm{s}$. It is also seen from the figure that there are a lot of thin portions (stress concentrated portions) existed on the body of the formed penetrator. These portions could split the penetrator into fragments.

Figure 6 plots the predicted axial momentum-time history for each EFP warhead element of model 1 . It is seen from the figure that both the penetrator and case momentums increase in positive direction under the action of Comp B detonation, whereas the base momentum increases in negative direction. The sign is associated to the flight direction of each warhead element. At $t=22.4 \mu \mathrm{s}$, the EFP attains its maximum momentum. Then, the EFP momentum remains constant during the rest of its formation process. In addition, both the base and case has zero momentum at $t=$ $22.4 \mu \mathrm{s}$. This is due to their deletion in formation process after the EFP attains its maximum momentum.

Figure 7 plots the predicted total mass-time history for each warhead element of model 1. It is clear from the figure that all of the liner has been transferred into explosively formed penetrator. This constant mass proves that no fragment disintegrates from the penetrator during its formation process. The predicted penetrator mass is about $165 \mathrm{~g}$. In addition, both the masses of case and base are constant from the start of the formation process up to the time of their deletion. This result confirms that no split occurs for case and base materials under the effect of Comp B detonation.

Figure 8 shows the predicted pressure-time history at each target point selected on the liner of model 1. It is seen from the figure that the peak pressure at each target point is occurred during the period of time up to $t=22.4 \mu \mathrm{s}$. Moreover, the maximum peak pressure is occurred at the target point No. 4 which is in contact with the detonated explosive. The subsequent peak pressures at the same target point are decreased with time. This may be attributed to the attained velocity of the liner, which increases with time during the period of time up to $22.4 \mu \mathrm{s}$. The value of peak pressures at respective target points depends on its place on liner relative to explosive detonation. After $\mathrm{t}=22.4 \mu \mathrm{s}$, the pressure at each target point has been diminished to zero.

Figure 9 plots the predicted velocity-time history at each target point selected on $\mathrm{C} 15$ steel liner of model 1 . It is shown from the figure that the velocity at each target point increases dramatically at the beginning of formation process under the action of 
explosive detonation. Because of the bad aerodynamic shape of the formed penetrator, the velocities of the target points no. 2, 3 and 4 slightly decrease during the rest of formation process. At the end of formation process, the whole portions of the formed penetrator attain the same velocity. The predicted final velocity of the formed penetrator is about $1700 \mathrm{~m} / \mathrm{s}$.

Autodyn-2D was also simulated the formation process for the EFPs of the other preliminary models. The main dimensions of the elements for the other preliminary warhead models are listed in Ref. [1]. Liner material for models no. 3 and 5 was C15 steel, whereas it was OFHC copper for models no. 2, 4 and 6. For each of the other preliminary models, similar trends of the code predictions for model-1 were obtained. The main features of different EFPs formed from the preliminary models are listed in Table 4. Moreover, Figure 10 shows the final penetrator shape resulted from each preliminary model after terminating its formation process. It is seen from the figure that all the formed penetrators, except that formed from model 2, have places of thin cross-sections. These could be a reason of fragments which exist on the front face of RHA after their ballistic field tests, cf. Ref. [1].

From the predicted results of the preliminary models, it can deduce that: (i) for C15 steel liners of models 1,3 and 5 , as the liner radius of curvature increases, the aspect ratio of EFP decreases and more hollow penetrator was formed, cf. Figs. 10 a, c and e. Similar results are obtained for OFHC copper liners, cf. Figs. $10 \mathrm{~d}$ and f, and (ii) as the liner radius of curvature decreases, more liner deformation occurs and a compact steel penetrator is formed, cf. Fig. 10a. The obtained results are consistent with that of MacMahon et al. [7]. In contrast, the copper liner with small radius of curvature gives fragments, which may be due to its lower E/V [5], cf. Fig. 10 b.

\section{(ii) Main Features and Formation Process Results of the Refined EFP}

Based on the present predicted results for preliminary models, the following must be considered in designing the refined warhead model: (i) C10 steel is selected as a liner material because it has more ductility and capability to absorb plastic energy than that of $\mathrm{C} 15$ steel, i.e it has a high E/N ratio; this can lead to more elongated penetrator without fragmentation, (ii) liner thickness must be variable; its maximum value is at the apex of liner, (iii) $\mathrm{C} 10$ steel must be subjected to heat treatment to diminish the internal stress which may be a reason for EFP fragmentation during its formation, and (iv) a high aspect ratio for Comp B is recommended. The input data for simulating the liner material into the code is listed in Table 3.

The aforementioned conditions in addition to a charge aspect ratio of 195/180 are considered in designing the refined warhead model. The refined warhead model has been simulated into Autodyn-2D code. The main data of this model is fed into the code. The code is run to predict its EFP formation process. Figure 11 presents the complete formation process of the refined model. It is seen from the figure that the formed EFP has good compactness compared to those obtained from the preliminary 
models. Also, the formed EFP seems to do not have ability for disintegration. The code predicts that the total time of EFP formation process is about $465.7 \mu \mathrm{s}$.

Table 4. Main features of EFPs obtained from the simulated preliminary warhead models.

\begin{tabular}{|c|c|c|c|c|c|c|c|}
\hline $\begin{array}{c}\text { Model } \\
\text { No. }\end{array}$ & $\begin{array}{c}\text { Radius } \\
\text { of } \\
\text { curv., } \\
\mathrm{R}[\mathrm{mm}]\end{array}$ & $\begin{array}{l}\text { Liner } \\
\text { material }\end{array}$ & $\begin{array}{c}\text { Penetr. } \\
\text { length, } \\
L_{p} \\
{[\mathrm{~mm}]}\end{array}$ & $\begin{array}{c}\text { Penetr. } \\
\text { dia., } \\
D_{\mathfrak{p}} \\
{[\mathrm{mm}]} \\
\end{array}$ & $\begin{array}{c}\text { Penetr. } \\
\text { aspect } \\
\text { ratio }\end{array}$ & $\begin{array}{c}\text { Penetr. } \\
\text { velocity, } \\
\mathrm{V}_{\mathrm{p}}[\mathrm{m} / \mathrm{s}]\end{array}$ & Remarks \\
\hline 1 & \multirow{2}{*}{78.0} & C15 & 79.4 & 31.2 & 2.5 & 170 & $\begin{array}{c}\text { Slight } \\
\text { compact }\end{array}$ \\
\hline 2 & & $\begin{array}{l}\text { OFHC } \\
\text { copper }\end{array}$ & 92.4 & 25.8 & 3.6 & 1600.0 & Fragments \\
\hline 3 & \multirow[b]{2}{*}{117.0} & C15 steel & 61.3 & 36.0 & 1.7 & 1740.0 & Hollow \\
\hline 4 & & $\begin{array}{l}\text { OFHC } \\
\text { copper }\end{array}$ & 99.5 & 31.0 & 3 & 1620.0 & Hollow \\
\hline 5 & \multirow[b]{2}{*}{240.0} & C15 steel & 57.7 & 40.0 & 1.44 & 1760.0 & Hollow \\
\hline 6 & & $\begin{array}{l}\text { OFHC } \\
\text { copper }\end{array}$ & 90.0 & 19.0 & 1.9 & 1620.0 & Hollow \\
\hline
\end{tabular}

The time histories of axial momentum and total mass for each element of the refined warhead model and the time histories of pressure and velocity at the target points (cf. Fig. 11a) are predicted, respectively. The time histories of axial momentum and total mass for the individual elements of the refined model give similar trends as that of model 1. Moreover, the time histories of pressure and velocity at each target point on liner give similar trends as that shown in the corresponding figures for model 1 . The attained maximum velocity for the formed EFP at the end of its formation process is $1760 \mathrm{~m} / \mathrm{s}$. The penetrator attains this velocity at $\mathrm{t}=240 \mu \mathrm{s}$.

\section{(iii) Parametric Study Using the refined EFP}

In the following, Autodyn-2D code is used to study the influence of some elements of the refined warhead model on EFP formation process. The effects of each studied parameter on the EFP shape, velocity, dimensions and the propensity to remain as one coherent mass are presented. The main goal of this study is to determine numerically the optimized warhead design that gives the compact EFP with high aspect ratio and capable of realizing the required performance into RHA. The studied parameters are: (i) explosive type, (ii) charge aspect ratio, and (iii) liner material.

The main input data of the refined warhead model are taken as the basic data in Autodyn-2D code. The studied parameters are changed individually relative to these basic data. Three groups have been considered in Autodyn-2D; these groups are designated by $A, B$ and $C$, respectively. The difference between these groups is the value of charge aspect ratio. Three different values for charge aspect ratios are considered; these in order are $0.5,0.75$ and 1.08. For each group, both explosive 
type and liner material have been changed individually. The code was run considering the change in one element of the considered warhead. The predicted results associated with the change of each element in the considered warheads are listed in Chapter 5 of Ref. [1]. For each considered warhead, these results include the penetrator velocity, length and diameter at the end of its formation process.

\section{(a) Influence of explosive type on EFP formation}

Three different types of energetic explosives were considered, these were Comp B, Octol and LX-14. The code was run to predict the influence of each type of explosive on each EFP formation process obtained from each considered warhead of group A. Warheads of this group had charge aspect ratios of 1.08; three liner materials, treated C10 steel, OFHC copper and Armco iron, were considered in the analysis. Input data to the code for Armco iron as liner material as well as Octol and LX-14 as charge materials are listed in Table 5, respectively.

The formation process results show that the EFPs of treated C10 steel have better intact compared with that obtain from the other liner materials which disintegrate during their formation. Moreover, the influence of $\mathrm{LX}-14$ charge on treated $\mathrm{C} 10$ steel leads to the increase in $L_{p} / D_{p}$ ratio compared to the other charges considered. This can be attributed to the acting pressure on liner material due to $L X-14$ detonation, which is high compared with that of other types of explosives. Due to this pressure, the penetrator attains a high velocity gradient between its portions. Therefore, this gradient allows the penetrator to lengthen-up and its total length increases at the end of its formation process. The obtained results are consistent with that of Schweiger and Pohl [6]. They studied the influence of different explosive materials on $L_{p} / D_{p}$ ratio of EFP and they recommended the use of energetic explosive to increase the kinetic energy and the ratio of $L_{p} / D_{p}$ of the formed penetrator. For warheads having the other charge aspect ratios, the code predicted results for group $B$ are similar to that of $A$, whereas the results of group $C$ indicates the integrity of formed penetrators as $L_{c} / D_{c}$ ratio decreases.

In addition, the influence of explosive type on the penetrator velocity and $L_{p} / D_{p}$ ratio of the formed EFPs resulted from treated C10 steel liner can be shown in Figs. 12 and 13 , respectively. These figures show that the replacement of Comp B explosive with more energetic explosive type as $L X-14$, leads to a formed penetrator with high velocity and high aspect ratio.

\section{(b) Influence of charge aspect ratio on EFP formation}

The charge aspect ratio is one of the most important design parameters that influences efficiently on EFP performance. The different selected values of charge aspect ratio have been considered in such analysis. For the same type of explosive, the influence of the charge aspect ratio on the formed penetrator shape could be predicted. Autodyn-2D predicts that the diameter of the formed penetrator increases with the decrease of charge aspect ratio. In addition, the formed EFPs have more disability to fragmentation when the charge aspect ratio decreases.

The influence of charge aspect ratio on penetrator velocity and aspect ratio of the formed EFPs resulted from treated C10 steel liners can be shown in Figs. 14 and 15, 
respectively. All obtained results predict that the increase in charge aspect ratio of the warhead model leads to a longer and more compact EFP with higher velocity. The recommended value of charge aspect ratio $\left(L_{c} / D_{c}\right)$ for the refined design of warhead model is unity. The obtained results are consistent with the experimental and numerical results of Held [8], and Weimann [2].

\section{c) Influence of liner material on EFP formation}

The liner material characteristics have a sensitive role on EFP formation. The ability of liner material to absorb energy during its deformation and forming an elongated integral penetrator under explosive action has direct dependence on its type. In the present analysis, three different liner materials are considered; treated C10 steel, OFHC copper and Armco iron. Their main data listed in the previous tables were fed individually into Autodyn-2D code. The code predicts that the copper EFPs with charge aspect ratio of 1.08 are disintegrated during their formation process under the action of Comp B; this may be due to their lower E/V ratio which depended mainly on the material mechanical properties. Because of the induced velocity gradient is not fully absorbed, the deformed liner produces a continuously stretching penetrator, which finally disintegrates. For the other considered models, the code predicts compact EFPs.

Figures 16 and 17 plot the influence of the liner material type on the penetrator velocity and its aspect ratio, respectively. The predicted results were consistent with that deduced by Kishore et al. [9] when they found experimentally that the tantalum (with higher E/V ratio) liner material produced a large and almost solid EFP in comparison to the Armco iron EFP which was hollow.

The parametric study considered herein determines the following: (i) the suitable material for constructing the liner and keeping its integrity during formation process is the treated $\mathrm{C} 10$ steel,

Table 5. Input data to the code for the Armco iron liner and charge types of Octol and LX-14, respectively.

\begin{tabular}{|c|c|c|c|c|}
\hline Parameter & $\begin{array}{c}\text { Armco } \\
\text { iron liner }\end{array}$ & Parameter & Octol & LX-14 \\
\hline Reference density $\left(\mathrm{g} / \mathrm{cm}^{3}\right)$ & $7.89 \mathrm{E}+00$ & Density $\left(\mathrm{g} / \mathrm{cm}^{3}\right)$ & 1.821 & 1.835 \\
\hline Bulk modulus $(\mathrm{kPa})$ & $1.64 \mathrm{E}+08$ & Parameter $\mathrm{A}(\mathrm{kPa})$ & $7.486 \mathrm{E} 8$ & $8.261 \mathrm{E} 8$ \\
\hline Spec. heat $(\mathrm{c} . \mathrm{v}).\left(\mathrm{J} / \mathrm{kg}{ }^{\circ} \mathrm{K}\right)$ & $4.52 \mathrm{E}+02$ & Parameter $\mathrm{B}(\mathrm{kPa})$ & $1.338 \mathrm{E} 7$ & $1.724 \mathrm{E} 7$ \\
\hline Reference temp. $\left({ }^{\circ} \mathrm{K}\right)$ & $3.0 \mathrm{E}+02$ & Parameter $\mathrm{r}_{1}$ & 4.5 & 4.55 \\
\hline Shear modulus $(\mathrm{kPa})$ & $8.0 \mathrm{E}+07$ & Parameter $\mathrm{r}_{2}$ & 1.2 & 1.32 \\
\hline Yield stress $(\mathrm{kPa})$ & $1.73 \mathrm{E}+05$ & C-J deton. velocity $(\mathrm{m} / \mathrm{s})$ & $8.48 \mathrm{E} 3$ & $8.8 \mathrm{E} 3$ \\
\hline Hardening exponent & $3.2 \mathrm{E}-1$ & C-J energy / unit vol. $\left(\mathrm{kJ} / \mathrm{m}^{3}\right)$ & $9.6 \mathrm{E} 6$ & $1.02 \mathrm{E} 7$ \\
\hline Hardening constant $(\mathrm{kPa})$ & $3.8 \mathrm{E}+5$ & C-J pressure $(\mathrm{kPa})$ & $3.42 \mathrm{E} 7$ & $3.7 \mathrm{E} 7$ \\
\hline Strain rate constant & $6.0 \mathrm{E}-02$ & Parameter, $\omega$ & $3.8 \mathrm{E}-01$ & $3.8 \mathrm{E}-01$ \\
\hline Thermal softening exp. & $5.5 \mathrm{E}-01$ & & & \\
\hline Erosion strain & 3.0 & & & \\
\hline Melting Temperature, $\left[{ }^{\circ} \mathrm{k}\right]$ & $1.79 \mathrm{E}+03$ & & & \\
\hline
\end{tabular}


(ii) a powerful explosive is necessary to be used as a charge for EFP warhead in order to attain the formed penetrator its maximum elongation and velocity; it is determined by the parametric study that the LX-14 explosive type attains the formed treated C10 steel penetrator a velocity of $2 \mathrm{~km} / \mathrm{s}$, (iii) the ratio of $L_{p} / D_{p}$ of the formed penetrator must be great in order to realize the required performance when the formed penetrator impacts onto target; a predicted suitable ratio of 3.93 is associated with the treated $\mathrm{C} 10$ steel penetrator when forming under the action of LX-14 explosive, and (iv) experimentation is needed to confirm the performance of the refined model after replacing its charge with LX-14 type.

\section{(iv) Penetration Results of EFPs Formed from Preliminary and refined Warhead Models}

In the following, the penetration process of the formed penetrators from both the preliminary model 1 and the refined designed model into a monolithic RHA of 150 $\mathrm{mm}$ thickness is studied, respectively. Each formed penetrator was modeled using a Lagrange-grid as the results of the formation stage. The target was also modeled using the same grid. The Lagrange-Lagrange interaction was activated to simulate the penetration of each penetrator into RHA.

The end stages of penetration for EFPs formed from both the preliminary and refined models can be shown in Fig. 18, respectively. In addition, the predicted total penetration depths for those EFPs are 48.5 and $93.3 \mathrm{~mm}$. Each depth is determined when the penetrator velocity into RHA reaches zero. For the penetrator formed from the refined design, the crater has great dimensions. For each EFP, the original penetrator is totally eroded and it remains somewhat a hemispherical shell.

By comparing the predicted penetration depth for both models, it is seen that the performance of the refined EFP is generally better than that of the preliminary one. This may be due to: (i) the value of charge aspect ratio $\left(L_{c} / D_{c}\right)$ in the refined model is about unity, (ii) Treated C10 steel is used as liner material which has a higher E/V ratio than $\mathrm{C} 15$ steel; this allows the penetrator to be elongated and no ability for its disintegration, and (iii) imparting the penetrator of the refined model a high impact velocity.

\section{CONCLUSIONS}

The following points could be drawn out from the present work:

- The formation process results for the preliminary EFPs prove their disabilities to realize the required performance due to the following: (a) bad selection of liner materials, C15 steel and OFHC copper; these materials disintegrate under the action of explosive detonation because of their low E/V ratios, and (b) their high charge aspect ratios (i.e. $L_{c} / D_{c}>1$ ).

- The refined warhead model has been designed considering the different refinements drawn from the predicted formation results of the preliminary EFPs; 
the main refinements are concerned with the use of: (i) treated $\mathrm{C} 10$ steel as liner material, (ii) variable liner thickness, and (iii) value of Comp B aspect ratio of 1.08 . A compact EFP with high aspect ratio and high velocity is formed upon detonating the refined warhead model.

- The parametric study of the refined model deduces that the high-speed compact EFP with high aspect ratio can be formed by using energetic explosive type, charge aspect ratio having unity, and low carbon content steel as liner material. This study proposes another refined warhead model; it is similar to the designed one but the Comp B is replaced by LX-14 explosive. Experimentation is needed to confirm the performance of the proposed refined model.

- The predicted penetration depth into RHA by the obtained EFP of the refined warhead model realizes the required performance; this EFP is capable of penetrating $80 \mathrm{~mm}$ depth into monolithic RHA.

\section{REFERENCES}

[1] E.A. Ibrahim, "Investigation of Explosive Formed Penetrator Phenomenon", M. Sc. thesis, M.T.C., Cairo, Egypt (2005).

[2] K. Weimann, "Research and Development in the Area of Explosively Formed Projectiles Charge Technology", Propellants, Explosives and Pyrotechnics, Vol.18, pp. 294-298 (1993).

[3] J. Carleone, "Explosively Formed Penetrators", Terminal Ballistics Conference, San Jose Hyatt (1987).

[4] D. Davison, A. Nordell and H. G. Ohlsson, "Theory and Experimental Verification of a Technique for Soft-Catch of Explosively Formed Penetrators", $16^{\text {th }}$ Int. Symp. on Ballistics, San Francisco, U.S. A. (1996).

[5] J. A. Zukas, C. A. Weickert and P. J. Gallagher, "Numerical Simulation of Penetration by Explosively formed Projectiles", Propellants, Explosives and Pyrotechnics, Vol.18, pp. 259-263 (1993).

[6] R. Schweiger and W. Pohl, "A Step Towards Computer Aided Engineering in the Field of Self Fragment Warhead Design", $8^{\text {th }}$ Int. Symp. on Ballistics, Orlando, U.S.A. (1984).

[7] J. MacMahon, P. D. Church, M. Furth and J. D. King, "Hydrocode Simulation Studies of 2D and 3D Tantalum EFPs", $17^{\text {th }}$ Int. Sympo. on Ballistics, Midrand, South Africa (1998).

[8] M. Held, "Explosive Formed Projectile", $3^{\text {rd }}$ Int. Symp. on Ballistics, Karlsruhe, West Germany (1977).

[9] P. kishore, S. Singh, T. Raychaudhuri and V. Sharma, "Influence of Material Properties in EFP Design and Performance", $16^{\text {th }}$ Int. Symp. on Ballistics, San Francisco, U.S.A. (1996).

[10] F. Rondot, "Performance of Tantalum EFP Simulants", $17^{\text {th }}$ Int. Symp. on Ballistics, Midrand, South Africa (1998).

[11] K. Weimann, A. Blache, M. Cauret, R. Laurensou, F. Gil and F. Rondot, "Terminal Ballistics Of EFPs with High L/D Ratio", $17^{\text {th }}$ Int. Symp. on Ballistics, Midrand, South Africa (1998).

[12] J. A. Zukas and W. P. Walters, "Explosive Effects and Applications", Springer, New York, U. S. A (1998).

[13] AUTODYN-2D, "Theory Manual", Revision 3.0, Century Dynamics Inc. (1997). 


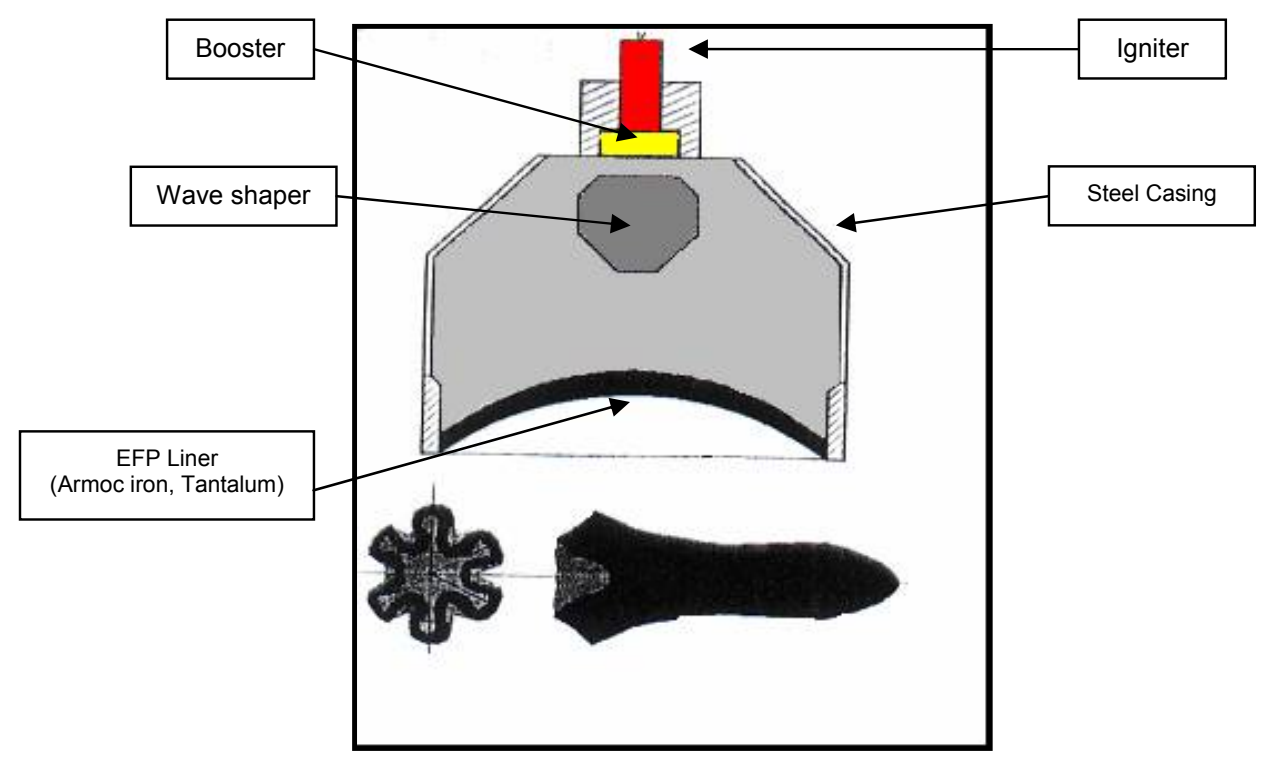

Fig.1. Scheme of a warhead that forms an EFP with star tail upon detonation [12].
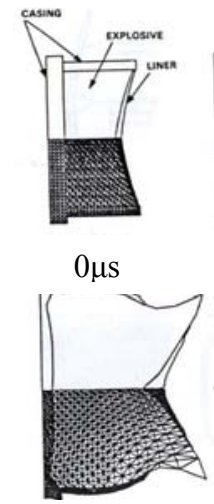

$35 \mu \mathrm{s}$

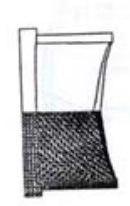

$10 \mu \mathrm{s}$

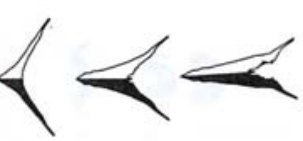

$40 \mu \mathrm{s} \quad 75 \mu \mathrm{s} \quad 100 \mu \mathrm{s}$

(a)

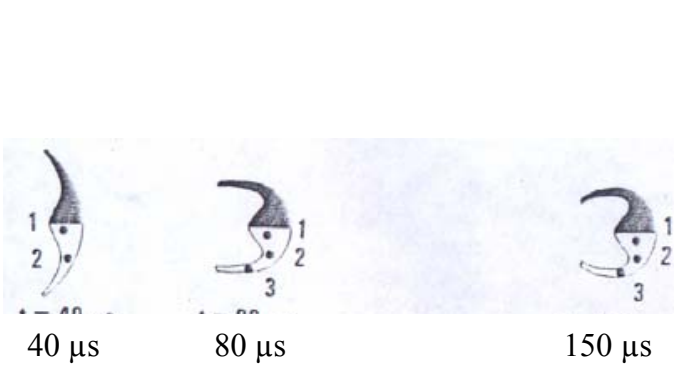

(c)
$35 \mu \mathrm{s}$

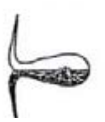

$100 \mu \mathrm{s}$

$200 \mu \mathrm{s}$

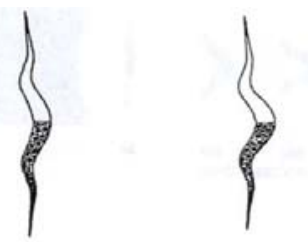

$40 \mu \mathrm{s}$

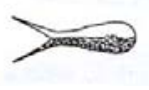

(b)
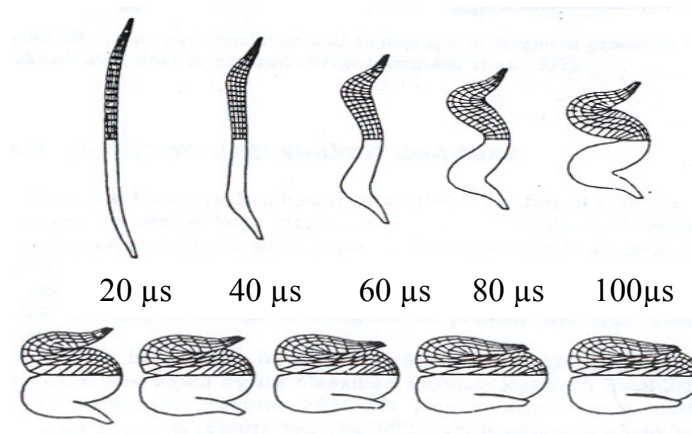

$120 \mu \mathrm{s} \quad 140 \mu \mathrm{s} \quad 160 \mu \mathrm{s} \quad 180 \mu \mathrm{s} \quad 200 \mu \mathrm{s}$

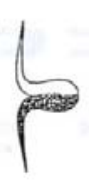

$75 \mu \mathrm{s}$

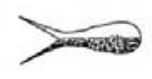

$250 \mu \mathrm{s}$ 


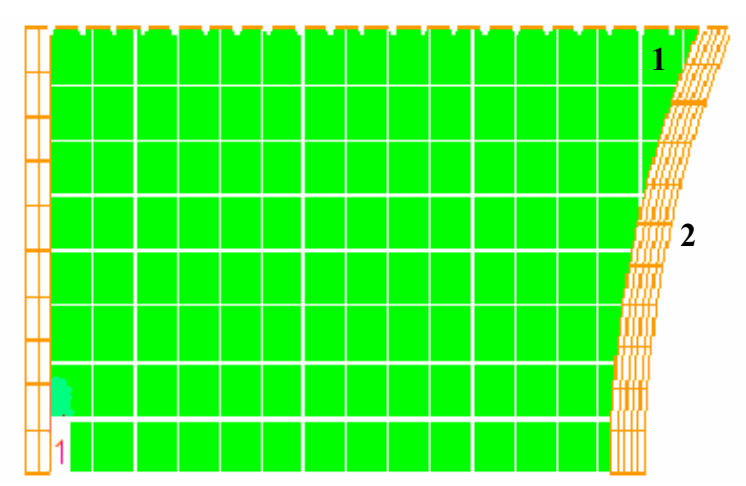

43
Fig. 3. Simulated EFP warhead with initiation and target points for model 1.

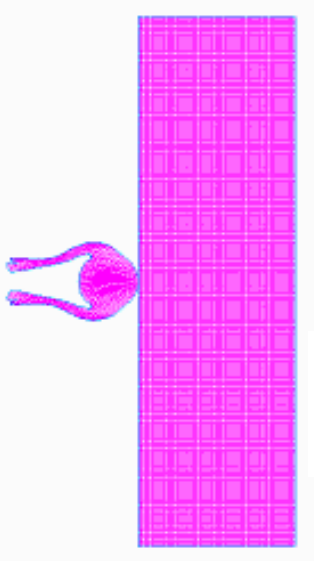

Cycle 11244

Time $644 \mu s$

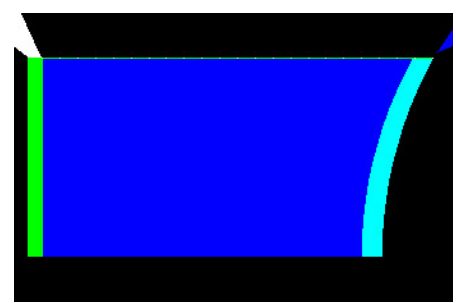

(a) $\mathrm{t}=0.0 \mu \mathrm{s}$

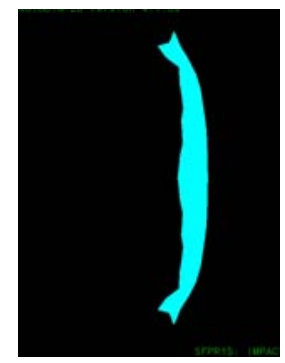

(c) $t=22.4 \mu \mathrm{s}$

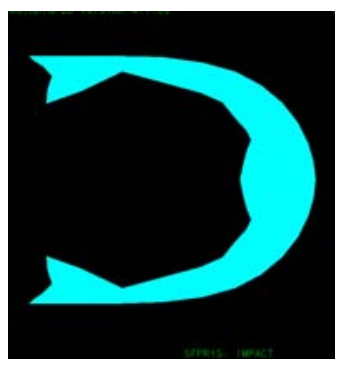

(d) $t=133 \mu \mathrm{s}$

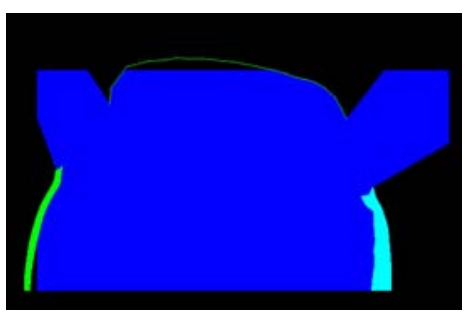

(b) $\mathrm{t}=22.4 \mu \mathrm{s}$

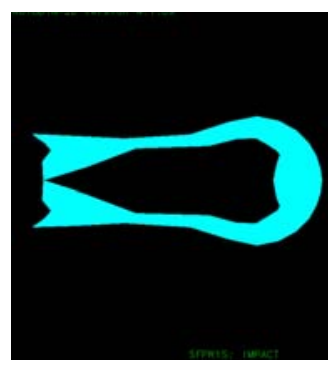

(e) $t=254 \mu s$

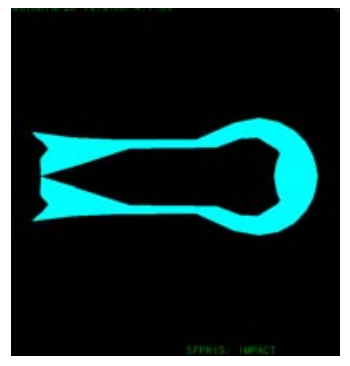

(f) $t=279 \mu \mathrm{s}$

Fig. 5. Formation process of EFP from C15 steel liner of model 1. 


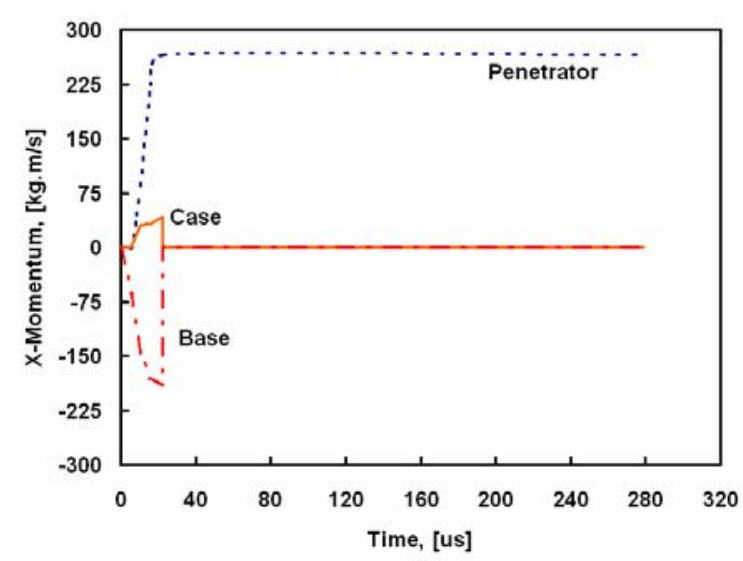

Fig. 6. X-momentum-time history for each element of Model 1.

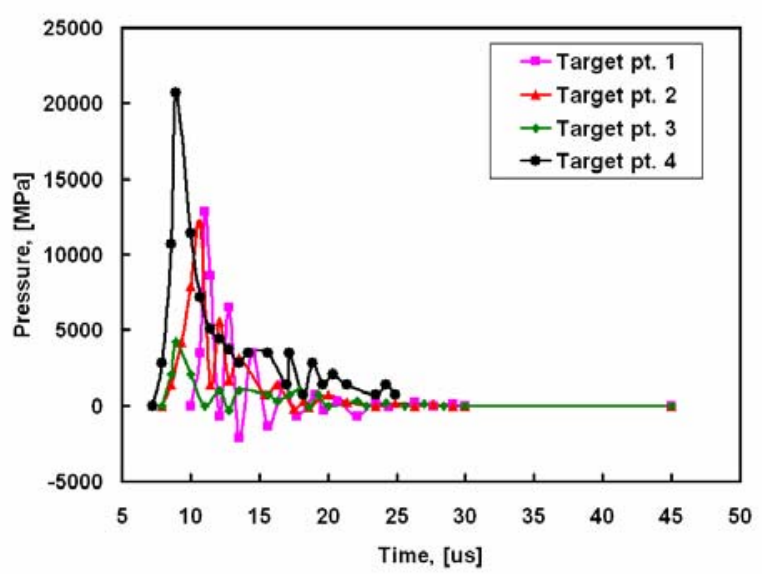

Fig. 8. Pressure-time history at each target point on $\mathrm{C} 15$ steel liner of Model 1

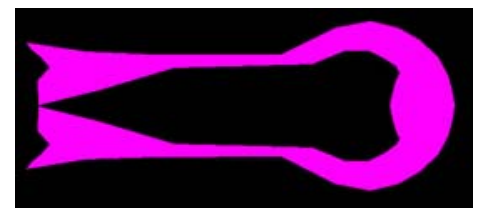

(a)

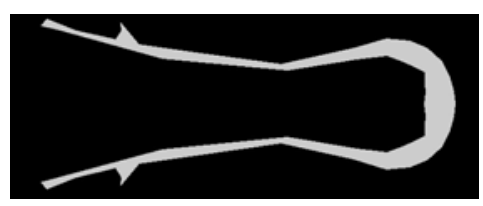

(d)

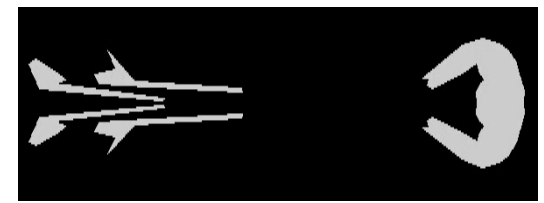

(b)

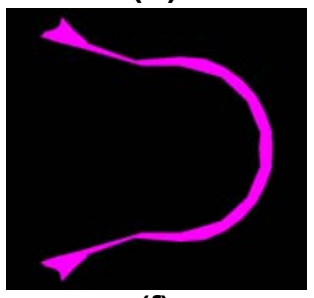

(f)

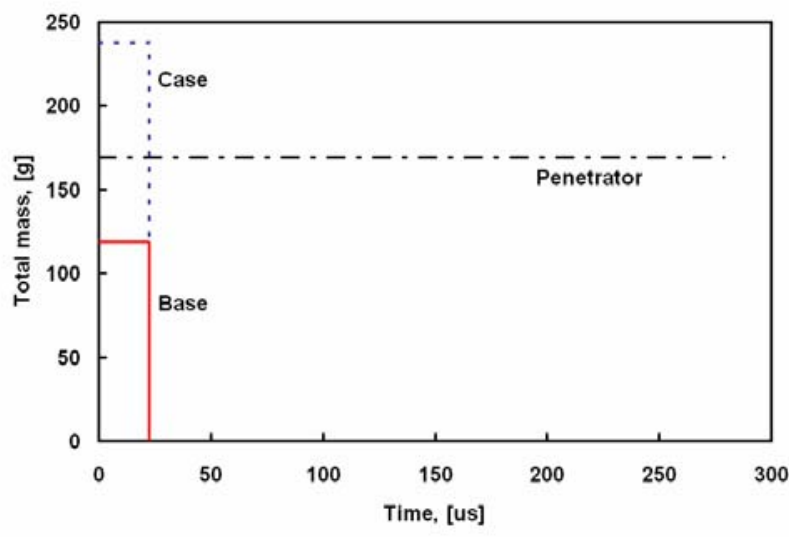

Fig. 7. Total mass-time history for each element of Model 1.

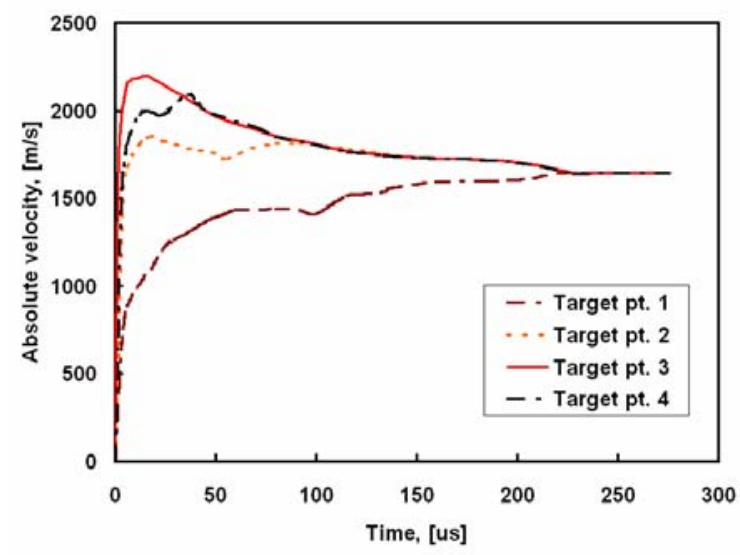

Fig. 9. Velocity-time history at each target point on C15 steel liner for Model 1.

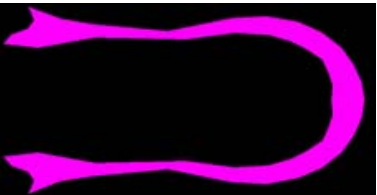

(c)

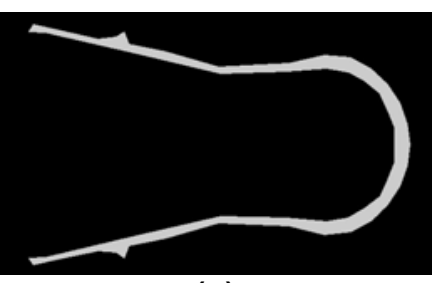

(g)

Fig. 10. Final EFP shapes formed from (a) Model 1, (b) Model 2, (c) Model 3, (d) Model 4, (e) Model 5, and (f) Model 6. 


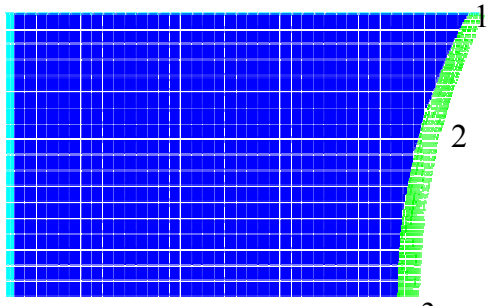

$\mathrm{t}=0.0 \mu \mathrm{s}$

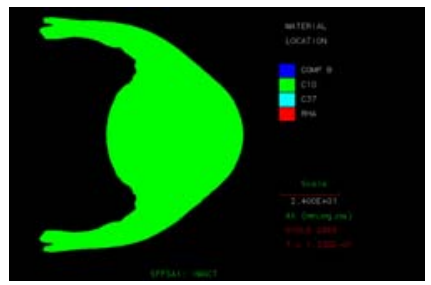

$t=133 \mu s$

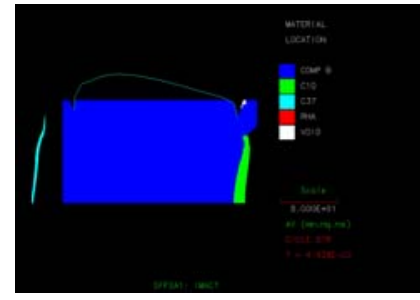

$\mathrm{t}=46.28 \mu \mathrm{s}$

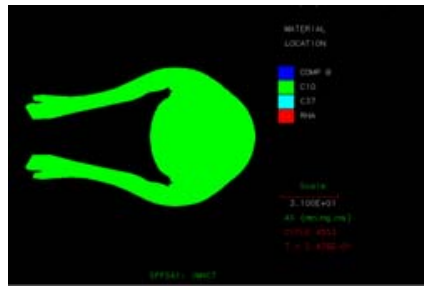

$\mathrm{t}=247.6 \mu \mathrm{s}$

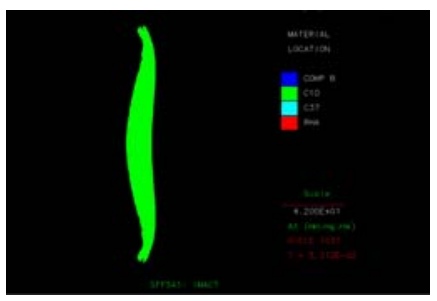

$\mathrm{t}=53.1 \mu \mathrm{s}$

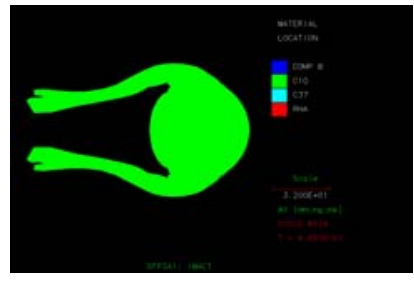

$\mathrm{t}=465.7 \mu \mathrm{s}$

Fig. 11. Formation process of EFP for the refined design with heat treated $\mathrm{C} 10$ steel liner having charge aspect ratio, Lc /Dc, of 195/180.

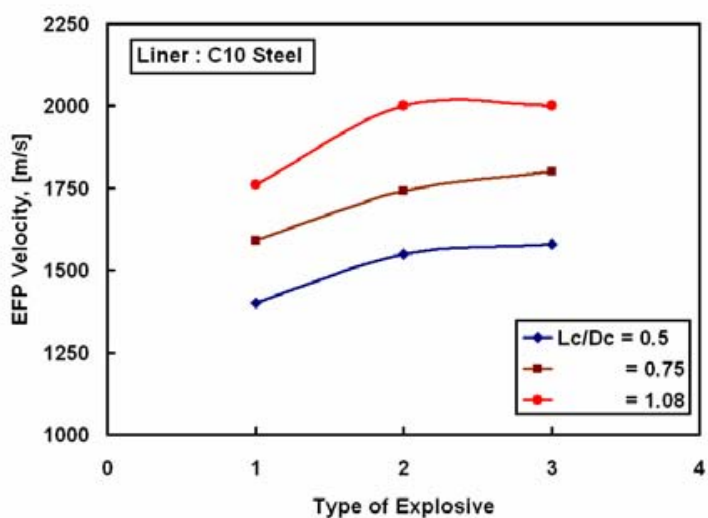

Fig. 12. Influence of explosive type on EFP velocity, where 1 designates Comp B, 2 Octol and 3 $\mathrm{LX}-14$ on the horizontal axis.

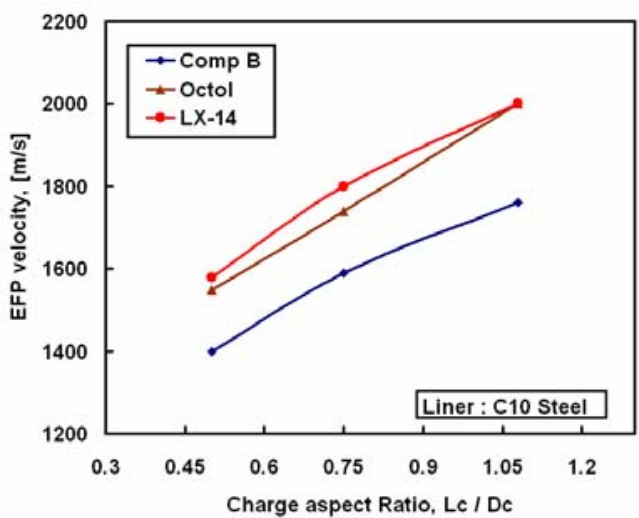

Fig. 14. Influence of $L_{c} / D_{c}$ ratio on EFP velocity.

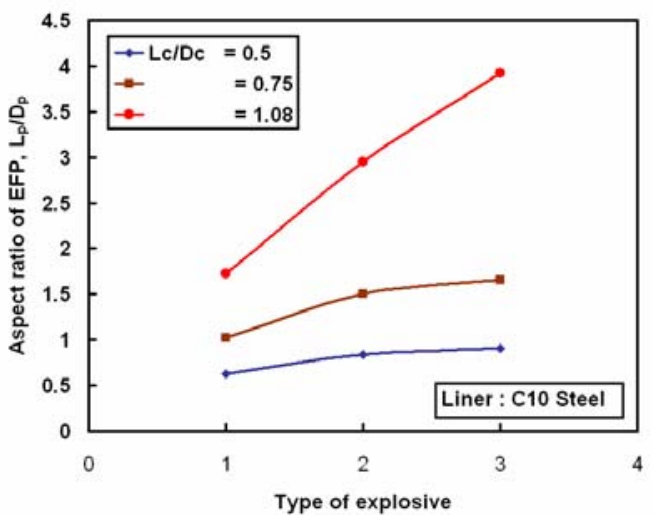

Fig. 13. Influence of explosive type on EFP aspect ratio, where 1 designates Comp B, 2 Octol and 3 $\mathrm{LX}-14$ on the horizontal axis.

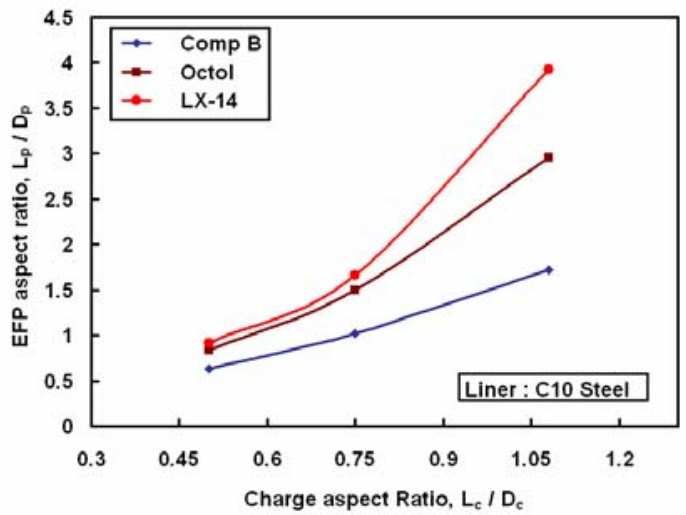

Fig. 15. Influence of $L_{c} / D_{c}$ ratio on EFP aspect ratio. 


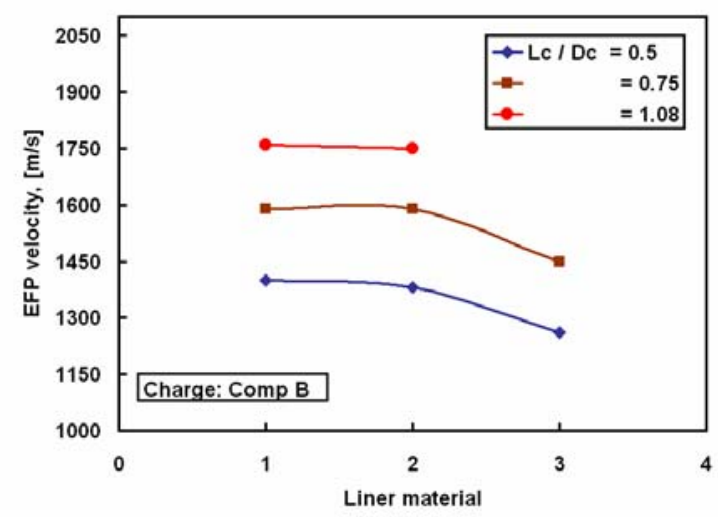

Fig. 16. Influence of liner material on EFP velocity, where 1 designates treated $\mathrm{C} 10$ steel, 2 Armco iron and 3 OFHC copper.

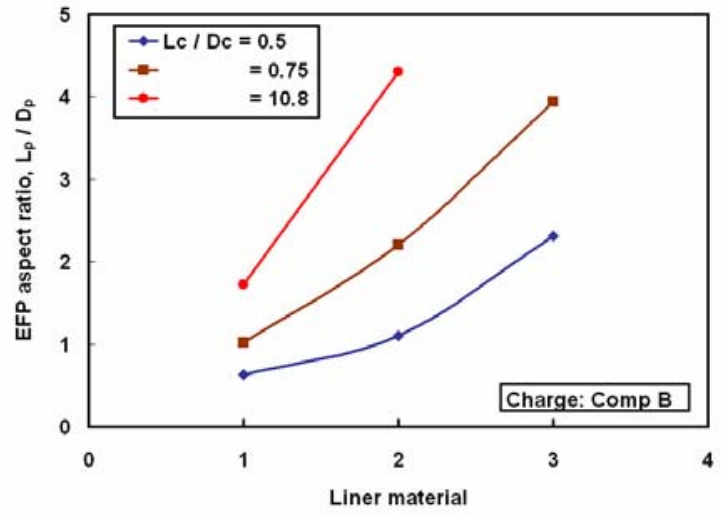

Fig. 17. Influence of liner material on EFP aspect ratio, where 1 designates treated $\mathrm{C} 10$ steel, 2 Armco iron and 3 OFHC copper.

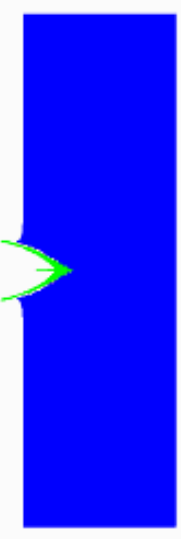

Material

location

C15 steel

RHA

Cycle 27803

Time $372.5 \mu \mathrm{s}$

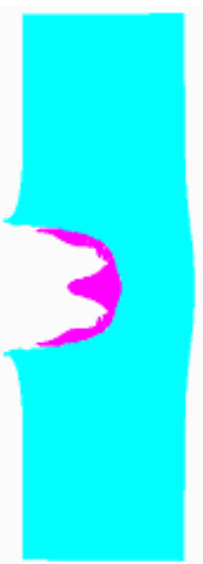

Cycle 52020

Time $860.7 \mu \mathrm{s}$

(a)

(b)

Fig.18. Predicted penetration depth into RHA for the penetrator formed from:

(a) preliminary Model 1 , and (b) refined model. 